\title{
Mechanical Properties of Particulate Coconut Shell and Palm Fiber Reinforced Polymer Matrix Composites
}

\author{
Sudarsono Sudarsono ${ }^{1}$, Hidayat Hidayat ${ }^{2}$, Rozaini Othman ${ }^{3}$, Aminur Aminur $^{4}$ \\ \{sudarsono@uho.ac.id ${ }^{1}$, hidayat@polnes.ac.id ${ }^{2}$, rozaini.othman@ppinang.uitm.edu.my ${ }^{3}$ \} \\ 1,4 Mechanical Engineering Departmen, Halu Oleo University, Indonesia \\ ${ }^{2}$ Mechanical Engineering Departmen, Politeknik Negeri Samarinda, Indonesia \\ ${ }^{3}$ Faculty of Mechanical Engineering, University Teknologi MARA, \\ Pulau Pinang, Malaysia
}

\begin{abstract}
The development of composites enters a new phase by utilizing natural fibers both as reinforcement or filler. The advantages of using natural materials are being environmentally friendly, abundant natural availability, and simple process. This study aimed to analyze the effect of adding fiber volume composition to the mechanical properties of palm epoxy-fiber composites. Coconut shells were grounded into powder with a size of $0.250 \mathrm{~mm}$, and palm fiber was cut to a size of $1.5 \mathrm{~mm}$ long. $10 \%$ palm fiber was mixed in epoxy resin by adding coconut shell powder to the composition of $65 \%$ epoxy, $25 \%$ powder; $60 \%$ epoxy, $30 \%$ powder; $55 \%$ epoxy, $35 \%$ powder, $50 \%$ epoxy, $40 \%$ powder. Each composition used the hand-lay-up method. The composite with $40 \%$ addition of powder had the tensile strength of $16.796 \mathrm{~N} / \mathrm{mm}^{2}$ and flexural strength of $14.608 \mathrm{~N} / \mathrm{mm}^{2}$. Tensile strength and flexural strength in each mixture composition significantly increased by adding $40 \%$ coconut shell powder, while elongation and deflection were decreased.
\end{abstract}

Keywords: Mechanical properties, particulate coconut shell, palm fibers, epoxy, composite.

\section{Introduction}

Environmental awareness and studies of natural fiber-reinforced polymer composites have sparked great interest in utilizing natural fibers as environmentally friendly and sustainable materials as an alternative to existing materials. In the past few years, the natural fiberreinforced polymer composites has developed significantly. The basic reason that natural fiber polymer composites are more environmentally friendly, lighter, abundant natural availability, biodegradable, and simpler manufacturing processes. Composites containing natural fibers have been used in transportation (automobiles, railway coaches, aerospace), military applications, building and construction industries (ceiling panels, partition boards), packaging, consumer products, and furniture (chairs, tables, showers, bath units) [1].

In general, composites are made when two or more materials combine together to provide a combination of properties that cannot be achieved when separated [2]. Based on its shape, the composite can be reinforced with fibers, particles, and structures [3]. Composites can also be made by combining two forms of reinforcement from fibers and fillers from particles to get better properties than a material with only fibers or particles. 
Based on their origin, natural fibers can originate from plants, minerals, and animals. Plant fibers can come from jute, hemp, kenaf,or sisal as well as extracts of pineapple, bagasse, oil palm,or coir [1]. Plant natural fibers can be obtained from several parts such as skin, stems, leaves, leaflets, seeds, and reeds.

Particles or powder can be obtained from metal, ceramic or can also come from natural materials such as coconut shell. A coconut treeis multipurpose as each of its partsis beneficial for human [4]. Natural lignocellulose such as coconut shell powder (Cocosnucifera) has tremendous potential as a plastic reinforcement [5]. Coconut shell has a hard layer consisting of lignin, cellulose, methoxyl, and various minerals. The hard structure is caused by silica $\left(\mathrm{SiO}_{2}\right)$ which is abundant in the shell [6]. The content of these ingredients varies according to the type of coconut family.

Among the several natural fibers studied, palm fiber is a natural fiber that has abundant availability but has not been utilized optimally. Palm fiber can be used as an alternative reinforcement for composite materials [2].

In general, composites consist of a matrix as an adhesive and fibers or fillers. Natural lignocellulose such as coconut shell powder has tremendous potential as reinforcement in plastic [6]. Coconut shells are the main filler for the development of new composites that are strong and they have a high modulus of fibers capable of reducing attenuation.

Epoxy is a copolymer that is formed from two different chemicals. This is referred to as "resin" and "hardener". Resins consist of monomers or short chain polymers with epoxide groups at both ends, while hardener consists of polyamine monomers. The main functions of the resin are to transfer pressure between the reinforcing fibers, act as glue to unite the fibers, and protect the fibers from mechanical and environmental damage [7].

This study aimed to analyze the effect of adding fiber volume composition on the mechanical properties of palm epoxy-fiber composites.

\section{Experimental Procedures}

\subsection{Material and Method}

The materials used in this study were epoxy resin (matrix), methyl ethyl ketone peroxide (catalyst), sodium hydroxide, mirror glaze, coconut shell particles, and palm fiber. Coconut shells that were made to particles were old coconut shells with good quality. Coconut shell particles were obtained by crushing the shell and sifted using 40 mesh for 10 minutes per sifting process.

A wire comb was used to clean palm fiber from various impurities and large-sized fibers. Palm fiber was immersed in an alkaline solution of sodium hydroxide 5\% for 2 hours then cleaned with distilled water. The treated fibersthen aerated and cut to a length of $15 \mathrm{~mm}$.

\subsection{Instruments and Testing}

The equipment used in the study were calipers, composite molds, universal testing and bending tests, digital scales, and other assistive devices.

Tensile testing is a mechanical evaluation for a material to determine its resilience and toughness to a certain stress and the elongation caused by the stress. The size of the composite material tensile test specimen referred to the ASTM D 638-01 standard. 
The tensile stress of composite material is calculated using Equation (1)

$$
\sigma=\frac{F}{A}
$$

where $\sigma$ is the stress of composite, $F$ is the load of composite and $A$ is the cross-sectional area of sample.

The elongation of composite material is calculated using Equation (2)

$$
\varepsilon=\frac{L_{1}-L_{0}}{L_{1}}
$$

where $\varepsilon$ is the elastic modulus of composite, $L_{1}$ is the composite length after break and $L_{2}$ is the composite length before break.

The elastic modulus of a composite material is calculated using Equation (3)

$$
E=\frac{\sigma}{\varepsilon}
$$

where $E$ is the elastic modulus of composite, $\sigma$ is the stress of composite and $\varepsilon$ is the elastic modulus of composite.

A bending test was performed to determine the bending and deflection strength formed by a composite material. The size of composite material bending test specimens referred to ASTM D 790-02 standards. The bending stress of a composite material is calculated using Equation (4):

$$
\sigma_{b}=\frac{3 F}{2 b d^{2}}
$$

where $\sigma_{b}$ is the bending stress of composite, $F$ is the load of composite, $L$ is the length of specimen, $b$ is the width of specimen and $h$ is thickness of specimen (mm).

The elastic modulus of a composite material is calculated using Equation (5):

$$
E_{b}=\frac{3 F L^{3}}{4 b d^{3} \delta}
$$

where $E_{b}$ is the bending modulus of composite, $F$ is the load of composite, $L$ is the length of specimen, $b$ is the width of specimen and $h$ is the thickness of specimen.

\section{Results and Discussion}

\subsection{Tensile strength}

Table 1 shows the values of tensile strength, modulus of elasticity, and elongation on each composite material composition. The lowest and highest tensile strength was found in the 
compositions of $25 \%$ and $40 \%$ fiber,which reached $12.960 \mathrm{~N} / \mathrm{mm}^{2}$ and $16.796 \mathrm{~N} / \mathrm{mm}^{2}$, respectively.Meanwhile, the lowest and highest modulus of elasticity was obtained by $25 \%$

Table 1. Effect of fiber volume concentration on tensile strength, modulus of elasticity, and elongation.

\begin{tabular}{cccc}
\hline $\begin{array}{c}\text { Volume Fraction } \\
(\%)\end{array}$ & $\begin{array}{c}\text { Tensile Strength } \\
\left(\mathbf{N} / \mathbf{m m}^{2}\right)\end{array}$ & $\begin{array}{c}\text { Modulus of Elasticity } \\
(\mathbf{G P a})\end{array}$ & $\begin{array}{c}\text { Elongation } \\
(\mathbf{m m})\end{array}$ \\
\hline 25 & 12.960 & 12.759 & 3.107 \\
30 & 13.204 & 12.968 & 2.910 \\
35 & 14.876 & 14.595 & 3.500 \\
40 & 16.796 & 16.444 & 2.567 \\
\hline
\end{tabular}

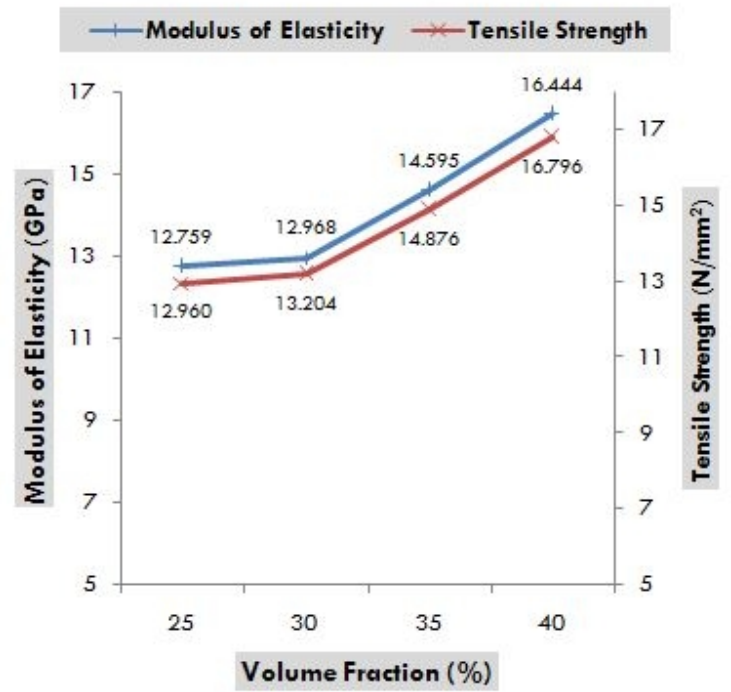

Fig 1. The relationship between tensile strength, modulus of elasticity, and fiber volume fraction.

and $40 \%$ fiber compositions with a respective value of $12.759 \mathrm{GPa}$ and $16.444 \mathrm{GPa}$. The lowest and highest elongation was found in the composition of $25 \%$ and $35 \%$ fiber with a value of $3.107 \mathrm{~mm}$ and $3.500 \mathrm{~mm}$, respectively.

The values of tensile strength and modulus of elasticity of composite materials can be seen in Figure 1. Tensile strength of $25 \%, 30 \%, 35 \%$, and $40 \%$ fiber composition reached $12.960 \mathrm{~N} / \mathrm{mm}^{2}, 13.204 \mathrm{~N} / \mathrm{mm}^{2}, 14.876 \mathrm{~N} / \mathrm{mm}^{2}$, and $16.796 \mathrm{~N} / \mathrm{mm}^{2}$, respectively. Meanwhile, the respective modulus of elasticity of $25 \%, 30 \%, 35 \%$, and $40 \%$ fiber composition were 12.759 GPa, 12.968 GPa, 14.595 GPa, and 16.444 GPa. Tensile strength and modulus of elasticity of composite materials significantly increased as the composition of coconut shell powder increased. Small coconut shell particles of $0,250 \mathrm{~mm}$ are capable of filling fiber- 
matrix gaps. With the increasing composition of coconut shell particles, the density of composite materials is increased. The hard layer of coconut shellsstrengthens the interaction of fiber-matrix and coconut shell particles.

\subsection{Bending strength}

Table 2 represents flexural strength, flexural modulus and deflection of specimens at different volume fraction. As can be seen in Table 2, the lowest and highest flexural strength was found in the composition of $25 \%$ and $40 \%$ fiber with a value of $9.357 \mathrm{~N} / \mathrm{mm}^{2}$ and 14.608 $\mathrm{N} / \mathrm{mm}^{2}$, respectively. Meanwhile, the lowest and highest flexural modulus was obtained in $25 \%$ and $40 \%$ fiber composition with respective values of $8.989 \mathrm{GPa}$ and $13.112 \mathrm{GPa}$. The lowest and highest deflection was found in $25 \%$ and $30 \%$ fiber composition with a value of $3.433 \mathrm{~mm}$ and $9.267 \mathrm{~mm}$, respectively.

Table 2. Effect of fiber volume concentration on flexural strength, flexural modulus, and deflection.

\begin{tabular}{cccc}
\hline $\begin{array}{c}\text { Volume Fraction } \\
(\%)\end{array}$ & $\begin{array}{c}\text { Flexural Strength } \\
\left(\mathbf{N} / \mathbf{m m}^{2}\right)\end{array}$ & $\begin{array}{c}\text { Flexural Modulus } \\
(\mathbf{G P a})\end{array}$ & $\begin{array}{c}\text { Deflection } \\
(\mathbf{m m})\end{array}$ \\
\hline 25 & 9.357 & 8.989 & 3.433 \\
30 & 9.583 & 8.965 & 9.267 \\
35 & 11.701 & 10.797 & 6.800 \\
40 & 14.608 & 13.112 & 5.800 \\
\hline
\end{tabular}

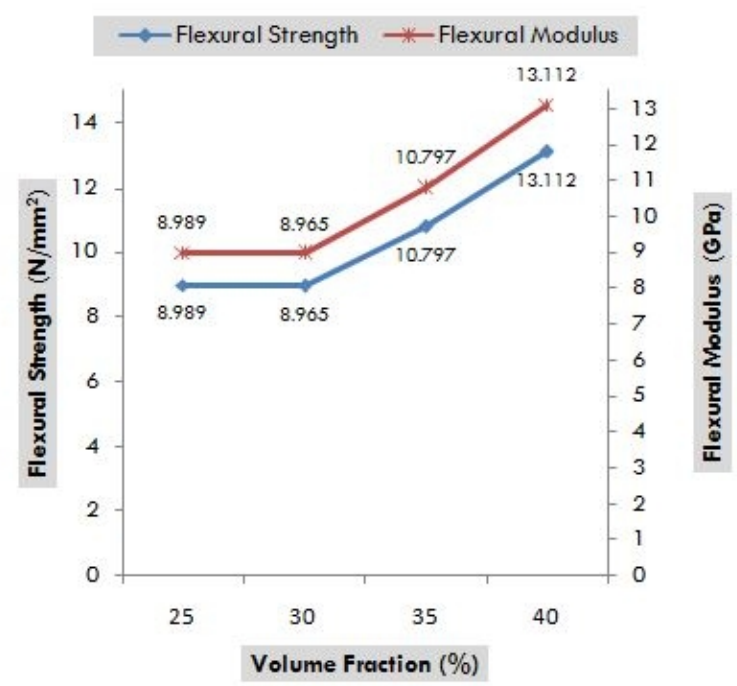

Fig2. The relationship between flexural strength, flexural modulus, and fiber 
The values of flexural strength and modulus of composite materials are displayed in Figure 2. Flexural strength of $25 \%, 30 \%, 35 \%$, and $40 \%$ fiber composition reached 8.989 $\mathrm{N} / \mathrm{mm}^{2}, 8.965 \mathrm{~N} / \mathrm{mm}^{2}, 10.797 \mathrm{~N} / \mathrm{mm}^{2}$, and $13.112 \mathrm{~N} / \mathrm{mm}^{2}$, respectively. Meanwhile, the respective flexural modulus of $25 \%, 30 \%, 35 \%$, and $40 \%$ fiber composition were $8.989 \mathrm{GPa}$, 8.965 GPa, $10.797 \mathrm{GPa}$, and $13.112 \mathrm{GPa}$. Flexural strength and modulus of composite materials significantly increased as the composition of coconut shell powder increased.The increase in flexural strength and modulus is caused by the absence of delamination in the fiber-matrix and interlocking of coconut shell particles on the fibers so that the fibers cannot shift.

\section{Conclusion}

The increasing coconut shell fiber concentration increased the tensile strength, elastic modulus, flexural strength, and flexural modulus. The addition of $40 \%$ coconut shell particle composition created a composite with tensile strength $=16.796 \mathrm{~N} / \mathrm{mm}^{2}$, elastic modulus $=$ 16.444 GPa, flexural strength $=14.608 \mathrm{~N} / \mathrm{mm}^{2}$, and flexural modulus $=13.112$ Gpa.Meanwhile, the lowest elongation of $2.567 \mathrm{~mm}$ was obtained by the composite with $40 \%$ fiber concentration while the lowest deflection of $3.433 \mathrm{~mm}$ was found at the composite with $25 \%$ fiber concentration.

\section{References}

[1] Udhayasankar, R. and Karthikeyan, B.: A Review on Coconut Shell Reinforced Composites. Chem Tech Research. Vol. 8, No.11 pp 624-637. India, 2015.

[2] Durowaye, S.I, Lawal, G.I, Akande, M.A, Durowaye, V.O.: Mechanical Properties of Particulate Coconut Shell and Palm Fruit Polyester Composites. Materials Engineering. Vol. 4 (4) pp 141-147. Nigeria, 2014.

[3] Callister, D.: Materials Science And Engineering An Introduction. United States Of America: John Wiley \& Sons, Inc., 2007.

[4] Amalia, L.S. Fadlan, A. Wahib, A.: Characteristics of Coconut Coir Composite Acoustic with Epoxy Matrix. Natural Sciences and Mathematics Research. Vol. 1 (2) pp 46-50. Indonesia, 2015.

[5] Agunsoye, J.O. Talabi, S. Isaac. Sanni, O. Samuel.: Study of Mechanical Behaviour of Coconut Shell Reinforced Polymer Matrix Composite. Minerals and Materials Characterization and Engineering. 11, 774-779. Nigeria, 2012.

[6] Sutikno, Marwoto P.M.S, Santiko, H.: Manufacture of Automotive Brake Pads. Unnes Press. ISBN 978602846740 7. Indonesia, 2011.

[7] Raagul, R. Kumar, R. P, Kumar, K.P.: Coconut Shell Reinforced Epoxy Composites. Engineering, Science and Management. Volume-1, Issue-11, ISSN: 2581-5792. India, 2018 . 